\title{
Secondary School Mathematics Teachers' Knowledge Levels and Use of History of Mathematics
}

\author{
Suphi Önder Bütüner \\ Correspondence: Suphi Önder Bütüner, Bozok University, Department of Mathematics and Science Education, Yozgat, \\ Turkey.
}

Received: October 23, 2017

doi:10.11114/jets.v6i1.2722
Accepted: November 20, $2017 \quad$ Online Published: November 28, 2017

URL: https://doi.org/10.11114/jets.v6i1.2722

\begin{abstract}
This study aimed to explore secondary school mathematics teachers' use of history of mathematics in their classes and their knowledge levels in this field. The population of the study comprised 58 secondary school mathematics teachers working at Yozgat city center, and the sample included 32 mathematics teachers from 10 schools who volunteered to take place in the study. These mathematics teachers were administrated an 11-item short-answer history of mathematics knowledge level test along with a 5-item written opinion form to identify their history of mathematics use. The findings showed that most teachers did not use history of mathematics in their classes, yet those who used history of mathematics did so by mentioning the life stories of mathematicians and the contributions of ancient civilizations to mathematics to motivate students at the beginning of their classes. The mean score of teachers who participate in this study at the history of mathematics knowledge test was computed 3.5 indicating that their knowledge levels concerning the history of mathematics were low. Additionally, it was found that those who did not use history of mathematics in their classes scored lower in the history of mathematics knowledge test than those who used it in their classes.
\end{abstract}

Keywords: mathematics teachers, history of mathematics, knowledge level, usage

\section{Introduction}

The use of history of mathematics in mathematics classes has been supported by many researchers (Arcavi, 1991; Fauvel, 1991; Bidwell, 1991; Ernest, 1998; Gulikers and Blom, 1998; Wilson and Chauvot, 2000; Fried, 2001; Tzanakis and Arcavi, 2002; Liu, 2003; Jankvist, 2009). The benefits of using it in classes may be summarized as follows: (1) It may help students understand that mathematics is a human activity and product (Fried, 2001; Tzanakis and Arcavi, 2002; Liu, 2003). (11) It may help raise students' motivation and develop a positive attitude towards learning (Swetz, 1997; Ernest, 1998; Furinghetti and Somaglia, 1998; Marshall and Rich, 2000, Liu, 2003; NCTM, 2006; Esteve, 2008). (111) It may develop student perspectives on the nature of mathematics and mathematical activities as well as teachers' instructional repertoire (Tzanakis and Arcavi, 2002; Liu, 2003). (iv) It may help the understanding of mathematical concepts, problems and solutions (Fried, 2001; Glukers and Blom, 2001; Tzanakis and Arcavi, 2002). Previous studies also report positive effects of history of mathematics on students' cognitive (Awosanya, 2001; Leng, 2006; Nataraj and Thomas, 2009; Lim, 2011, Lim and Chapman, 2015; Bütüner, 2016) and affective development (Lawrence, 2006; Haverhals and Roscoe, 2010; Lim, 2011; Bütüner, 2014; Lim and Chapman, 2015) in mathematics class.

In addition to the reasons for using history of mathematics in mathematics classes, the literature also includes various views about how history of mathematics may be used (Fried, 2001; Tzanakis and Arcavi, 2002; Glaubitz, 2007; Jankvist, 2009). Fried (2001) discusses two strategies for the use of history of mathematics in classes. The addition strategy involves activities such as the use of historical anecdotes, mathematicians' life stories, historical problems or photos of mathematicians in the classroom. With this approach, the existing curriculum is not changed, only expanded. The other approach is the adaptation strategy. Similar to Katz adapting Napier's logarithm to today's classes, this strategy teaches topics by adapting them to a historical schema. Jankvist (2010) refers to using history of mathematics in order to increase students' attitudes towards mathematics, their motivation or academic success as the use of history of mathematics as a means, while he refers to using history of mathematics to show that mathematics changes and develops based on time, place and culture, that it has developed and shaped throughout history with the contribution of different cultures, and that the human factor has a vital role in this development as the use of history of mathematics as a goal. Tzanakis and Arcavi (2002) list the following ways for using history of mathematics: "historical snippets (life stories, works, pictures, etc.), research projects based on historical texts, primary sources, worksheets, historical 
packages, errors, alternative concepts, historical problems, mechanical tools, experimental mathematics activities, games, films and other visual components, trips to historical places, the internet".

In Turkey, historical content was integrated into secondary school mathematics textbooks with the curriculum renewal in 2004. The general goals of the mathematics curriculum points to the need for teachers to use history of mathematics in their classes. The secondary school mathematics curriculum states the following about the use of history of mathematics in classes: "Knowing about the historical development of mathematics may enable secondary school students to develop a positive attitude towards mathematics and its learning. HoM is full of many important and interesting characters and anecdotes. Sharing information about these historical characters, their lives, works and contributions to mathematics will render the mathematics course more meaningful for students. For example, students who are familiarized with Euclid, one of the most prominent geometricians in Ancient Greece, and his best-known work Elements can see that today's geometry topics originated at least 2500 years ago and were transferred from one culture to another as historical heritage. There have been many other mathematicians in the history of humans. The mathematics program recommends that HoM is shared with students in order for students to develop a positive view of mathematics and the mathematics class, and to understand it better. For instance, sharing a few interesting details from Pythagoras' life as his theory is being taught may increase students' motivation to learn" (TTKB, 2013). These explanations in the curriculum imply that historical content to be used in classes may entail mathematicians' life stories, works, contributions to mathematics, and anecdotes. These are historical snippets (Tzanakis and Arcavi, 2002).

The curriculum stresses that the use of historical snippets may make students realize that mathematics is a cultural heritage and it may give them a positive attitude towards mathematics. In light of Jankvist's (2009) work and considering how history of mathematics is used in secondary school mathematics textbooks in Turkey, enabling students to realize that mathematics is a cultural heritage is an example of using history of mathematics as a goal and giving them a positive attitude towards mathematics is an example of using history of mathematics as a tool.

Regardless whether history of mathematics is used as a goal or a tool, there is a consensus in the literature that it should be part of the instructional environment. Similar to Turkey, many other countries have made space in their mathematics curricula for history of mathematics and they support its use in classes. Therefore, teachers' use of history of mathematics may be researched to identify existing deficiencies and take necessary measures. Many limitations are known to hamper the use of history of mathematics. These limitations include lack of time, lack of teacher knowledge and experience in using history of mathematics, the mismatch between the topics of history of mathematics and mathematics tests, and lack of materials (Tzanakis and Arcavi, 2002; Siu, 2007; Horton, 2011; Panasuk and Horton, 2012). The low history of mathematics knowledge level of teachers may be another limitation before using it in the classroom. Previous studies have shown the low level of history of mathematics knowledge that teachers have (Alpaslan, 2011; Gazit, 2013). The present study is necessitated by the fact that there is no previous study which simultaneously identifies mathematics teachers' classroom use and knowledge levels of history of mathematics in Turkey. In addition, the results of the study may also guide secondary school mathematics curriculum designers and teacher training institutions. In light of the information above, it seems important to identify teachers' history of mathematics knowledge levels and, at the same time, their history of mathematics use. The problems of the study are:

Problem 1: To what extent do mathematics teachers use history of mathematics in their classes?

Do mathematics teachers use history of mathematics in their classes?

What are the reasons for mathematics teachers not to use history of mathematics in their classes?

In what ways and for what purposes do mathematics teachers use history of mathematics in their classes?

How much time do mathematics teachers allocate in their classes for the history of mathematics?

Do mathematics teachers view themselves as competent in the use of history of mathematics?

Problem 2: What is teachers' history of mathematics knowledge level?

\subsection{Previous Studies}

In order for mathematics teachers to be able to use historical content in their classes, they need to have at least basic historical knowledge about the concepts in the textbooks. Goodwin (2007) studied the relationship between the image of mathematics on high school mathematics teachers' minds and their HoM knowledge levels. Data were collected from 193 teachers through surveys sent to schools. Teachers' HoM knowledge levels were tested through questions involving the activities of matching mathematicians' names and eras, recognizing the mathematician who fits a given situation, chronologically ordering historical events, and choosing the right historical era for a given situation. The study concluded that most teachers' history of mathematics knowledge levels were low.

Ho (2008) investigated whether and how teachers used HoM in their classes, and what barriers existed to its use. In line 
with this purpose, data were collected from 1,000 teachers by questionnaires. The findings showed that more than $90 \%$ of teachers did not use HoM in their courses. Of those who made use of the historical approach in their mathematics class, $9 \%$ used historical snippets, $6 \%$ used mechanical tools, $4 \%$ used historical problems, $3 \%$ used primary resources, $3 \%$ used the internet, $1 \%$ used worksheets, $1 \%$ used experimental mathematics activities, and $1 \%$ used errors and alternative concepts. According to the findings from the questionnaires, teachers listed the following as barriers to using HoM: Lack of teachers training in using the historical approach $(16,9 \%)$, lack of time $(16,9 \%)$, confusion caused by the historical approach $(16,9 \%)$, and history not being the same as mathematics $(16,9 \%)$. Other most common barriers were the lack of appropriate evaluation scales $(13,2 \%)$, lack of resources $(9,4 \%)$, students not caring for activities based on the historical approach as these are not evaluated $(9,4 \%)$, and the dislike that students have for history $(7,5 \%)$.

Smestad (2008) tried to identify teachers' mental images of HoM. Data were collected from four teachers of different ages and different education levels, two of whom were working at a secondary school and the remaining two at a high school. The first teacher (T1) had been working at a secondary school for 10 years. This teacher stated that he was thinking of the exams that students would take, HoM was not part of the exams and students needed a few more years to be able to understand HoM. These were his reasons for not using HoM in his classes. The second teacher had been working at a high school for 40 years (T2), and she stated that she used HoM at the beginning of class as a lead-in. She used anecdotes and mathematicians' life stories in a maximum of five minutes. The third teacher, who had also been working at a high school for 40 years, (T3) reported not to spend time on HoM. The final teacher, who had been working at a secondary school for 10 years (T4), was the one who used HoM most frequently. T1 could not exemplify how he was using HoM in his classes. T2 reported using anecdotes and life stories as lead-in to increase motivation. T4 stated that she used HoM in 1-2 month small projects.

Alpaslan (2011)'s thesis attempted to identify mathematics teacher candidates' history of mathematics knowledge levels via an 11-item test. Four of these items were multiple choice, 2 were True-False, and 5 were short answer and gap fill questions. Overall, the test items revolved around the contributions of different civilizations and individuals to the historical development of mathematics and historical instructional tools. In this study, responses were coded as 'right' and 'wrong (no answer)' and scored as 1 and 0 , respectively. The test mean scores of mathematics teacher candidates was 0,44 , which was rather low. The same questions were asked to 178 sixth graders, 179 seventh graders and 142 eighth graders and their mean score was found to be , an inadequate level (Alpaslan and Bostan, 2016).

Gazit (2013) aimed to identify HoM knowledge levels of mathematics teachers and teacher candidates. Participants were 29 mathematics teachers and 71 mathematics teacher candidates. Data were collected by using a 10-item multiple choice test. The first eight questions focused on scientists in different fields of mathematics. Two questions involved the contributions of cultures to mathematics. According to data obtained from the test, the mean achievement was $40,1 \%$. Gazit interpreted teacher achievement in three categories based on the test results. Question 5 was in the first category. The achievement rate for the question "Who wrote the book The Foundations of Plane Geometry?" was $83 \%$. Questions $1,2,3,4$ and 8 were included in the second category and their right answer percentages ranged between $40 \%-44 \%$. Almost half of the participants did not know the roots of our number system, what caused the appearance of the eceived sequence, where the name cartesian coordinates system comes from, when Pythagoras lived, or who first used simple fractions. The right answer percentages of questions 6, 7, 9 and 10 in the third category were between $22 \%-28 \%$. The participants were found to not know when the probability principle was first coined, what mathematician calculated the pi number, where the word algorithm came from, and who found natural numbers.

Panasuk and Horton (2012) studied whether mathematics teachers used HoM in their classes and their reasons. Data were collected from 367 mathematics teachers via surveys. Of the respondents, 133 stated using HoM in their classes and 204 stated not to. Among the reasons for using HoM were increasing students' interest and attitudes towards mathematics, student enjoyment in learning the history of mathematical concepts, and students seeing the relationships between mathematical concepts. They emphasized they also enjoyed instruction with HoM and valued it. The teachers who did not use HoM in their classes gave the following reasons: their lack of adequate knowledge and skills about the use of HoM, lack of resources, lack of time, the lack of congruence between the topic and the exams the students were to take.

A general look at these studies shows that teacher and teacher candidates have a low level of knowledge in history of mathematics, and most did not use it in their classes. Those who used history of mathematics generally used it to get students' attention through historical snippets. Below is the methods section.

\section{Method}

No intervention (manipulation) took place in the analyzed environment in this study, and the existing situation was reflected as accurately as possible. Therefore, the study may be said to be a descriptive study (Cohen, Manion and Morrison, 2007). In this section, information will be supplied on the population and sample, data collection tools and 
data analyses.

\subsection{Participants}

The population of the study comprised 58 secondary school mathematics teachers working at Yozgat city center, and the sample included 32 mathematics teachers from 10 schools who volunteered to take place in the study. The facts that the sample covered $55 \%$ of the population and included teachers with different experience levels suggest adequate representation of the population. The names of the schools where the teachers were working are not specified here, and the teachers are coded as T1, T2, T3.

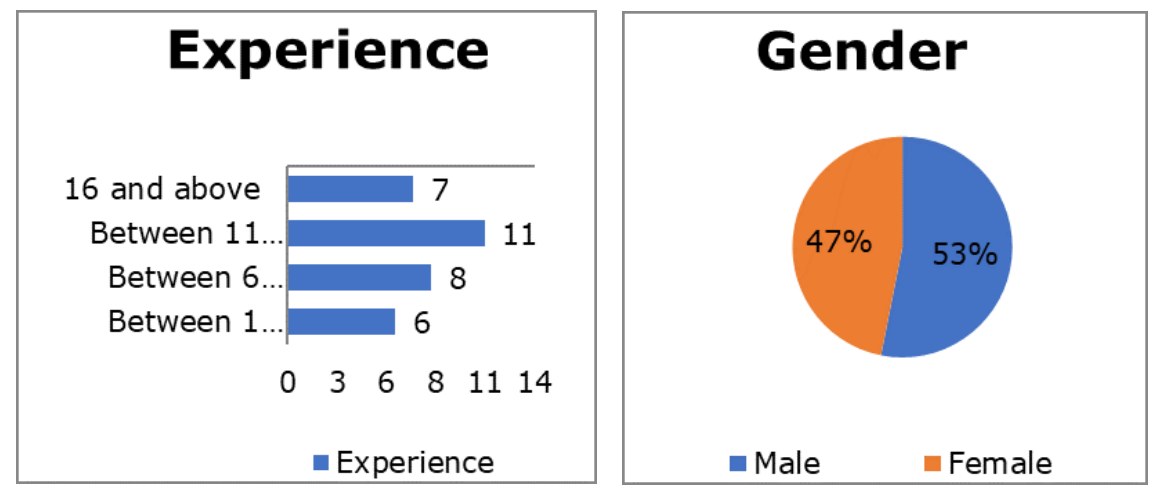

Figure 1. Demographics of participants by gender (a) and experience (b)

\subsection{Data Collection Tools}

A question form including 11 short answer questions was used in order to identify the history of mathematics knowledge levels of secondary school mathematics teachers. The questions were prepared by considering previous studies in the literature (Goodwin, 2007; Alpaslan, 2011; Gazit, 2013), contents and objectives in the secondary school mathematics textbooks, and historical content in textbooks (Commission, 2011; Aygün et al., 2011a; Aygün et al., 2011b). The content validity of the test was ensured by having it reviewed by one academic with studies on history of mathematics and 2 mathematics teachers. Questions 1, 3, 7, 9,10 and 11 aim to test knowledge of mathematicians and civilizations, question 8 aims to test knowledge of mathematics sub-branches, question 4 tests knowledge of the starting point of the Fibonacci sequence, question 5 tests awareness of the pi number, question 2 tests knowledge of female mathematicians in history, and question 6 tests knowledge of various mathematicians who proved the Pythagorean relation. The first pilot trial of the test was performed on 4 mathematics teachers with 0-5, 6-10, 11-15, and 16-20 years of experience, and the teachers were asked to report in written form whether any of the questions were unintelligible and whether any of them were not related to the content of the mathematics textbook. All teachers stated that all of the items on the test were intelligible and congruent with the contents of the textbook. Teachers competed the test in approximately 30 minutes. The second pilot trial was undertaken with 64 teacher candidates who had taken the history of mathematics class at the elementary mathematics education program at a state university in Turkey. KR-20 reliability coefficient is used to estimate the reliability of obtained scores when dealing with dichotomous (binary) data (Wright \& Stone, 1999) so KR-20 reliability coefficient is used to estimated the reliability in this study and KR-20 reliability coefficient of the test was found as 0.81 . Generally, reliability estimates above 0.70 indicate an acceptable level (Erwin, 2000). The test may therefore said to have a desirable level of reliability.

In order to identify secondary school mathematics teachers' use of history of mathematics, a 5-item written opinion form was used. The first item asked teachers whether they used history of mathematics in their classes and their reasons. The second item inquired in which ways and how they used history of mathematics in their classes, while the third item asked their purposes for using history of mathematics. The fourth and fifth items inquired whether the teachers had previously taken any hands-on training in using history of mathematics and whether they viewed themselves as competent in using history of mathematics, respectively.

\subsection{Data Analysis}

Teachers responses to the question form consisting of 11 short answer questions were scored by assigning 0 point for incorrect responses or no response, and 1 point for correct responses. The data collected to discover secondary school mathematics teachers' use of history of mathematics in their classes were analyzed by using descriptive analysis. Data from the teachers were analyzed and tabulated under the categories of ways of using history of mathematics, purpose of using history of mathematics, teacher competence in using history of mathematics. Frequency and percentage values were used to present the data. Teacher views were also quoted. 


\section{Results}

\subsection{Findings about Mathematics Teachers' Use of History of Mathematics in Their Classrooms}

The first two questions of the 5-item written opinion form aimed to identify whether mathematics teachers used history of mathematics in their classes, and if yes, through what ways. The findings are presented in Table 1.

Table 1. The Ways Teachers Use History of Mathematics in Their Classes

\begin{tabular}{lcc}
\hline Ways of Using History of Mathematics & $\mathrm{f}$ & $\%$ \\
I use it as I teach formula, who found and proved them. & 2 & 6 \\
I use contributions of different civilizations to mathematics and the life stories of mathematicians. & 9 & 28 \\
I use works of mathematicians. & 4 & 13 \\
I do not use history of mathematics. & 17 & 53 \\
\hline
\end{tabular}

Table 1 shows that more than half of the teachers stated not using history of mathematics in their classes. Namely, teachers coded as T2, T5, T6, T7, T10, T11, T15, T16, T17, T18, T20, T22, T24, T26, T28, T31 and T32 stated that they did not use history of mathematics in their classrooms. In their responses, 7 teachers blamed not using history of mathematics on "the lack of a link between history of mathematics and the tests to be taken by students", 6 on "lack of time", and 4 on "their lack of knowledge and experience in using history of mathematics". It was found that 9 teachers (T3, T4, T12, T13, T19, T21, T23, T25, T27) included in their classes the life stories of mathematicians or the contributions of different civilizations to mathematics. Four teachers (T8, T9, T29, T30) mentioned mathematicians' works in their classes, and two (T1, T14) mentioned the mathematician who found the formula and validated it when teaching formulas. Below are several teachers quotes:

T8 “When teaching the Pascal triangle, I mention that the first person to find it was Omar Khayyam. I also mention that Harezmi was the first to discover zero."

T25 "I show videos on the interactive board to impart information about the historical content of mathematics. I show videos introducing ancient Greek, Mesopotamian, and especially Turkish-Islamic mathematicians."

T27 "I assign some prominent mathematicians as research assignment."

T9 "I use it briefly as theories and formula are known by the names of the people who created them."

T4 "I don't use it. I don't think history of mathematics is related to the exams students will take."

T11 "I hardly go through the curriculum, therefore I have no time to use history of mathematics."

$\mathrm{T} 7$ "I don't use history of mathematics as I don't have enough information on the topic."

The third question of the written opinion form asked teachers why they used history of mathematics in their classes. Findings based on teacher responses to this question are presented in Table 2.

Table 2. The Times and Reasons that Teachers Use History of Mathematics

\begin{tabular}{lllll}
\hline Reasons for Using History of Mathematics & f & $\%$ & Time \\
\hline To get students' attention when introducing a topic & 9 & 28 & $0-5$ mins \\
\hline To make mathematics more fun and to increase their motivation & 6 & 19 & $0-5$ mins
\end{tabular}

Of the teachers, 9 (T3, T8, T9, T12, T21, T25, T25, T27, T29) stated that they used history of mathematics in order to get students' attention, while 6 (T4, T8, T13, T19, T23, T30) stated that they used it to make mathematics fun and to increase students' motivation. Teachers' historical content use time ranged between 0-5 minutes. Some teachers views are below:

Ö19 'Often to increase students' motivation. Using a theory or method that a mathematician has developed as an example increases motivation."

Ö8 "To show them how intelligent the mathematicians were; how they conducted research; to convince them that they can also do similar things."

Ö25 "I start the lesson with the life story of a prominent mathematician related to the day's topic, for instance Harezmi, and try to get students' attention in the topic." 
In questions 4 and 5, teachers were asked to state whether they received hands-on training in the use of history of mathematics and whether they felt competent in using history of mathematics, respectively. Findings from teacher responses to these questions are shown in Table 3.

Table 3. Teacher Competence in Using History of Mathematics

\begin{tabular}{llll}
\hline Teacher Competence in Using History of Mathematics & $\mathrm{f}$ & $\%$ \\
\hline I have been trained in using history of mathematics in classes. & Adequate & 0 & 0 \\
\cline { 2 - 4 } & Inadequate & 11 & 34 \\
\hline $\begin{array}{l}\text { I have not been trained in using history of mathematics in } \\
\text { classes. }\end{array}$ & Adequate & 0 & 0 \\
\cline { 2 - 4 } & Inadequate & 21 & 66
\end{tabular}

Although no teacher reported to have received in-service training in the use of history of mathematics, 11 teachers stated that they took the course history of mathematics during their undergraduate education. All respondents believed they did not possess enough knowledge or skills in using history of mathematics. Teacher views include:

Ö11 "No, I don't feel competent because I didn't receive any training. In my senior year at university, I took a course. I only share basic information at the beginning of class to get students' attention".

Ö6 "I don't feel competent. I have no idea where, how and when to use it".

Ö4 "I have deficiency in this. I took the history of mathematics course at university. But the course only taught us about the life stories of mathematicians and their works. I didn't take any other in-service training." The next section offers the findings on teachers' history of mathematics knowledge levels.

\subsection{Findings about Teachers' Knowledge Levels in History of Mathematics}

Appendix 1 presents the 11 items of the history of mathematics knowledge test, along with the numbers and percentages of teachers who responded correctly and incorrectly. Teachers' responses to each question are presented in Table 4.

The mean history of mathematics knowledge test score of the teachers who participated in the study was 3.5. This finding shows that the teachers in general had low history of mathematics knowledge levels. The analysis showed that items 1, 2, 8 and 10 had the lowest correct response percentages. No teachers answered items 2, 8 or 10 correctly. Only one teacher responded correctly to item 1, which was "Which two cultures is our current decimal number system based on?" The items most commonly answered correctly were 3, 5 and 11. Questions 3 and 5 were answered correctly by 24 teachers, and question 11 was answered correctly by 26 teachers. The numbers of teachers who answered questions 4,6 , 7 and 9 correctly were $6,9,11$ and 11 , respectively. The next section presents findings about the relationship between the use of history of mathematics and knowledge levels in the field. 
Table 4. Teachers' performance on test questions

\begin{tabular}{|c|c|c|c|c|c|c|c|c|c|c|c|c|}
\hline Teacher & Q1 & Q2 & Q3 & $\mathrm{Q} 4$ & Q5 & Q6 & Q7 & Q8 & Q9 & Q10 & Q11 & Total Score \\
\hline $\mathrm{T} 1$ & 0 & 0 & 1 & 0 & 1 & 0 & 1 & 0 & 1 & 0 & 1 & 5 \\
\hline$* T 2$ & 0 & 0 & 1 & 0 & 1 & 0 & 0 & 0 & 0 & 0 & 0 & 2 \\
\hline $\mathrm{T} 3$ & 0 & 0 & 1 & 0 & 1 & 1 & 1 & 0 & 1 & 0 & 1 & 6 \\
\hline $\mathrm{T} 4$ & 0 & 0 & 1 & 1 & 0 & 1 & 1 & 0 & 1 & 0 & 1 & 6 \\
\hline *T5 & 0 & 0 & 0 & 0 & 0 & 0 & 0 & 0 & 0 & 0 & 1 & 1 \\
\hline *T6 & 0 & 0 & 1 & 0 & 1 & 0 & 1 & 0 & 0 & 0 & 1 & 4 \\
\hline$* T 7$ & 0 & 0 & 0 & 0 & 1 & 0 & 0 & 0 & 0 & 0 & 1 & 2 \\
\hline $\mathrm{T} 8$ & 1 & 0 & 1 & 1 & 1 & 1 & 1 & 0 & 1 & 0 & 1 & 8 \\
\hline T9 & 0 & 0 & 1 & 1 & 1 & 1 & 1 & 0 & 1 & 0 & 1 & 7 \\
\hline *T10 & 0 & 0 & 1 & 0 & 1 & 0 & 0 & 0 & 0 & 0 & 1 & 3 \\
\hline *T11 & 0 & 0 & 1 & 0 & 1 & 0 & 0 & 0 & 0 & 0 & 0 & 2 \\
\hline T12 & 0 & 0 & 1 & 0 & 1 & 0 & 0 & 0 & 1 & 0 & 1 & 4 \\
\hline $\mathrm{T} 13$ & 0 & 0 & 1 & 0 & 1 & 0 & 0 & 0 & 0 & 0 & 0 & 2 \\
\hline T14 & 0 & 0 & 1 & 0 & 1 & 0 & 0 & 0 & 0 & 0 & 1 & 3 \\
\hline *T15 & 0 & 0 & 0 & 0 & 0 & 0 & 0 & 0 & 0 & 0 & 1 & 1 \\
\hline *T16 & 0 & 0 & 1 & 0 & 1 & 0 & 0 & 0 & 0 & 0 & 0 & 2 \\
\hline *T17 & 0 & 0 & 1 & 0 & 1 & 0 & 0 & 0 & 0 & 0 & 1 & 3 \\
\hline$* T 18$ & 0 & 0 & 1 & 0 & 1 & 0 & 0 & 0 & 0 & 0 & 1 & 3 \\
\hline T19 & 0 & 0 & 1 & 1 & 1 & 1 & 1 & 0 & 1 & 0 & 1 & 7 \\
\hline$* T 20$ & 0 & 0 & 0 & 0 & 0 & 0 & 0 & 0 & 0 & 0 & 1 & 1 \\
\hline $\mathrm{T} 21$ & 0 & 0 & 1 & 0 & 1 & 1 & 1 & 0 & 1 & 0 & 1 & 6 \\
\hline$* T 22$ & 0 & 0 & 1 & 0 & 1 & 0 & 0 & 0 & 0 & 0 & 0 & 2 \\
\hline $\mathrm{T} 23$ & 0 & 0 & 1 & 0 & 1 & 0 & 0 & 0 & 0 & 0 & 1 & 3 \\
\hline$* T 24$ & 0 & 0 & 0 & 0 & 0 & 0 & 0 & 0 & 0 & 0 & 1 & 1 \\
\hline $\mathrm{T} 25$ & 0 & 0 & 1 & 1 & 1 & 1 & 1 & 0 & 1 & 0 & 1 & 7 \\
\hline$* T 26$ & 0 & 0 & 1 & 0 & 0 & 0 & 0 & 0 & 0 & 0 & 1 & 2 \\
\hline $\mathrm{T} 27$ & 0 & 0 & 1 & 1 & 1 & 1 & 1 & 0 & 1 & 0 & 1 & 7 \\
\hline$* T 28$ & 0 & 0 & 0 & 0 & 0 & 0 & 0 & 0 & 0 & 0 & 1 & 1 \\
\hline T29 & 0 & 0 & 1 & 0 & 1 & 0 & 0 & 0 & 0 & 0 & 1 & 3 \\
\hline T30 & 0 & 0 & 1 & 0 & 1 & 1 & 1 & 0 & 1 & 0 & 1 & 6 \\
\hline *T31 & 0 & 0 & 0 & 0 & 1 & 0 & 0 & 0 & 0 & 0 & 1 & 2 \\
\hline *T32 & 0 & 0 & 0 & 0 & 0 & 0 & 0 & 0 & 0 & 0 & 0 & 0 \\
\hline Total Score Mean & & & & & & & & & & & & 3.5 \\
\hline
\end{tabular}

*Teachers who do not use history of mathematics

Despite the overall low knowledge levels of the teachers who participated in the study, it was found that those who did not use history of mathematics in their classes scored lower in the history of mathematics knowledge test than those who used it in their classes. The total test scores of the teachers who use and do not use the history of mathematics are given in Figure 2.

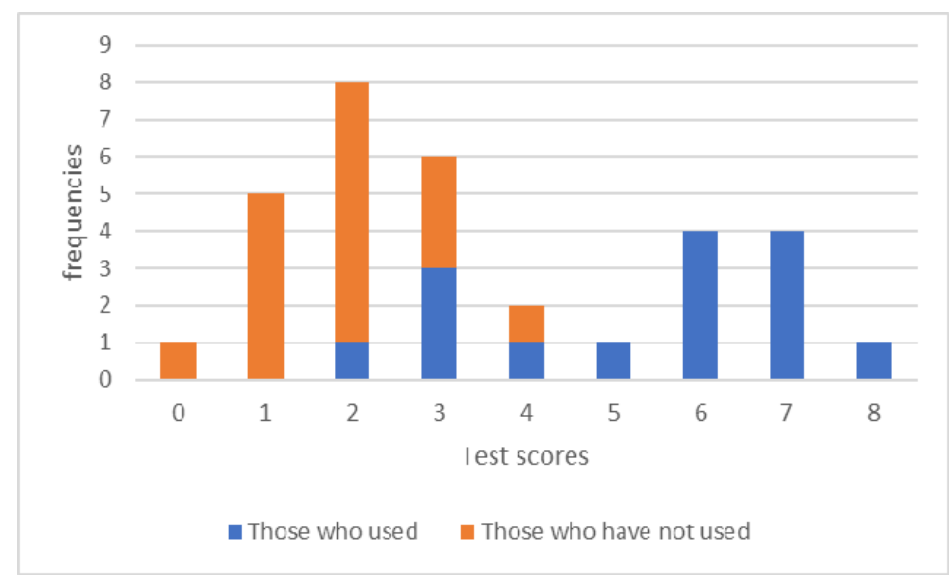

Figure 2.The total test scores of the teachers who use and do not use the history of mathematics 
While the mean test score of teachers who used history of mathematics in their classes was 5.33, that of teachers who did not use it was 1.88. Of the 17 teachers who did not use history of mathematics in their classes, T32 scored 0; T2, T5, T7, T11, T15, T16, T20, T22, T24, T26, T28 and T31 scored 1 or 2; T10, T17 and T18 scored 3; and T6 scored 4 in the test. Of those who used history of mathematics in their classes, T12, T13, T14 and T29 scored between 2 and 4; and T1, T3, T4, T8, T9, T19, T21, T25, T27, T30 scored between 5 and 8.

\section{Discussion and Conclusion}

This study aimed to describe the use of history of mathematics by secondary school mathematics teachers and their knowledge levels in this field, as well as to reveal the relationship between the two variables. Regarding teachers' history of mathematics use, more than half of them did not use it in their classes and found themselves incompetent in using history of mathematics. In addition, they stressed that they did not prefer to use history of mathematics due to lack of time and the incongruence between history of mathematics and the exams students were to take. Similar conclusions have been reached in other studies in the literature (Ho, 2008; Smestad, 2008; Panasuk and Horton, 2012). More than $90 \%$ of the 1.000 teachers in Ho (2008)'s study reported not to use history of mathematics in their classes. Their reasons included "lack of knowledge in using history of mathematics", "lack of time" and "lack of interest in mathematics". One out of the four teachers in Smestad (2008)'s study reported not to use history of mathematics in her classes as the topic is not covered in the exams that students are to take and for fear that young students would not understand history of mathematics. Panasuk and Horton (2012)'s study included 367 mathematics teachers. Of these, 133 were observed not to use history of mathematics in their classes. They explained their reasons as follows: Lack of adequate knowledge and skills in the use of history of mathematics, lack of resources and time, mismatch between the topic and future exam content.

It was found that teachers who used history of mathematics in their classes used the life stories and works of mathematicians and the contributions of ancient civilizations to mathematics. These show that teachers use history of mathematics only by using short historical snippets. Teachers used history of mathematics at the beginning of a new topic, in order to motivate students to learn and to get their attention. Also, the time teachers spent on historical content ranged between 0-5 minutes. Results about mathematics teachers' methods of and reasons for using history of mathematics in their classes showed that teachers embraced the "views emphasized in the mathematics curriculum about how history of mathematics could be used in the classroom". However, the literature stresses that only using mathematicians' life stories, pictures or works is not enough and such use of history of mathematics renders students passive (Swetz, 1997; Fried, 2001). Therefore, it seems that using historical content in such a way as to make students learn by doing and to help them construct mathematical concepts, rules and formula will be more beneficial for students. Indeed, previous studies also mention the positive effects of using this type of content on students (Glaubitz, 2007; Nataraj and Thomas, 2009; Bütüner, 2014; Bütüner, 2015; Bütüner, 2016). However, this does not suggest that using mathematicians' life stories and works in the classroom, or the contributions of ancient civilizations to mathematics, is not beneficial. Parallel to these conclusions, one of the 4 teachers in Smestad (2008)'s study reported that she used history of mathematics through anecdotes and mathematicians' life stories at the beginning of class to motivate the students, and did not exceed five minutes. In addition, TIMSS 1999 revealed that, out of 638 mathematics lessons observed, only 3\% made room for history of mathematics and that the time allocated for history of mathematics was limited only to three minutes. History of mathematics mostly involved mathematicians' life stories, but did not involve activities that would require students to carry out work into history of mathematics (Smestad, 2008). These findings are parallel to those reached in the study.

These results reveal the need to train teachers in the use of history of mathematics and integrating it into their classes. Teachers may be offered in-service training about how to prepare and implement historical content to help students learn by doing and construct mathematical concepts, rules and formula on their own. Studies on this topic reveal that teachers and teacher candidates find hands-on training about using history of mathematics in instructional settings beneficial and state that training enriches their teaching repertoire (Hickman and Kapadia, 1983; Bell, 1992; Gönülateş, 2008; Huntley and Flores, 2010).

Findings about the second research problem showed that teachers' mean score from the history of mathematics knowledge test was 3.5, thus suggesting a low knowledge level overall. Even though three-fourths of the teachers answered questions 3,5 and 11 correctly, they were not able to display the same performance in other questions. Teachers did not know about any female mathematicians, the roots of trigonometry taught in grade 8 textbook, or the works of Harezmi, the mathematician whose models are included in grade 8 textbook. Only one teacher knew the culture out of which the decimal number system was born (Indo-Arabian). Approximately one-fourth of the teachers knew the problem that led to the origination of the Fibonacci sequence, the works of the Greek mathematician Euclid, a mathematician other than Pythagoras himself who proved the relation, or the ancient Egyptian number system. These findings suggest that teachers' history of mathematics knowledge levels are low. This finding corroborates other studies 
in the literature (Goodwin, 2007; Alpaslan, 2011; Gazit, 2013). Similarly, Gazit (2013) found that approximately half of the teachers did not know the roots of our number system, the reason for the origination of the fibonacci sequence, or the roots of the word algorithm. Another noteworthy finding was that teachers who use history of mathematics in their classes have higher knowledge levels in this field than those who do not use it. While the mean test score of teachers who use history of mathematics was 5.33, that of others was 1.88. This finding suggests that having historical knowledge about the concept to be taught may be important in the use of history of mathematics in classes.

In conclusion, it was found that the mathematics teachers who participated in the study had a low knowledge level in history of mathematics. Parallel to this, many teachers stated that they did not use history of mathematics in their classes and found themselves incompetent to do so. Considering the emphasis on using history of mathematics in mathematics curricula and the research reports in the literature revealing the positive effects of using history of mathematics, it is obvious that teachers need at least a basic level of historical knowledge about the concepts they are to teach. In-service training programs may be organized by expert academics in history of mathematics in order to inform teachers about the historical development of the mathematical concepts included in the curriculum. In this way, teachers will gain historical knowledge about the concepts they are to teach, and also become encouraged to make use of history of mathematics in their classes.

\section{References}

Alpaslan, M. (2011). Prospective elementary mathematics teachers' knowledge of history of mathematics and their attitudes and beliefs towards the use of history of mathematics in mathematics education (Unpublished thesis), Middle East Technical University, Turkey.

Alpaslan, M., \& Bostan, M. I. (2016). Middle school students' knowledge of history of mathematics and their attitudes and beliefs towards using history in school mathematics. Hacettepe University Journal of Education, 31(1), $142-162$.

Arcavi, A. (1991). Two benefits of using history. For the learning of mathematics, 11(2), 11.

Awosanya, A. (2001). Using history in the teaching mathematics (Unpublished thesis), Florida State University, America.

Aygün Ç. S, Aynur, N., Çuha, S. S., et al. (2011a). Mathematics 7 student textbook. Ankara: Ministry of Education Publications.

Aygün, Ç. S., Aynur, N., Coşkuntürk, N., et al. (2011b). Mathematics 8 student textbook. Ankara: Ministry of Education Publications.

Bell, J. G. (1992). A history of mathematics class for middle school teachers (Unpublished thesis), Illinois State University, America.

Bidwell, J. (1993). Humanize your classroom with the history of mathematics. The Mathematics Teacher, 86(6), 461-464.

Bütüner, S. Ö. (2014). Reflections from Classrooms Enriched with History of Mathematics: An Action Study. Unpublished Thesis, Turkey: Karadeniz Technical University

Bütüner, S. Ö. (2015). Using history of mathematics to teach volume formula of frustum pyramids: dissection method. Universal Journal of Educational Research, 3(12), 1034-1048. https://doi.org/10.13189/ujer.2015.031213

Bütüner, S. Ö. (2016). The use of concrete learning objects taken from the history of mathematics in mathematics education. International Journal of Mathematical Education in Science and Technology, 47(8), 1156-1178. https://doi.org/10.1080/0020739X.2016.1184336

Cohen, L., Manion, L., \& Morrison, K. (2007). Research methods in education (6th ed.). London: Routledge

Commission (2011). Mathematics 6 student textbook. Ankara: Ministry of Education Publications.

Ernest, P. (1998). The history of mathematics in the classroom. Mathematics in School, 27(4). 25-31.

Erwin, T. D. (2000). The NPEC sourcebook on assessment, volume 1: Definitions and assessment methods for critical thinking, problem solving, and writing. Harrisonburg, VA: Center for Assessment and Research Studies, James Madison University.

Esteve, R. M. (2008). Understanding mathematics through its history. Third ICESHS, Austrian Academy of Sciences, Vienna.

Fauvel, J. (1991). Using history in mathematics education. For the Learning of Mathematics, 11(2), 3-6.

Fried, N. M. (2001). Can mathematics education and history of mathematics coexist? Science and Education, 10, 
391-408. https://doi.org/10.1023/A:1011205014608

Furinghetti, F., \& Somaglia, A. M. (1998). History of mathematics in school across disciplines. Mathematics in School, 27(4), 48-51.

Gazit, A. (2013). What do mathematics teachers and teacher trainees know about the history of mathematics? International Journal of Mathematical Education in Science and Technology, 44(4), 501-512. https://doi.org/10.1080/0020739X.2012.742151

Glaubitz, M. R. (2007). The use of original sources in the classroom. Proceedings of the 5th European Summer University, Prague.

Gönülateş, F. O. (2004). Prospective teachers' views on the integration of history of mathematics in mathematics courses (Unpublished thesis), Bogazici University, Turkey.

Goodwin, D. M. (2007). Exploring the relationship between high school teachers' mathematics history knowledge and their images of mathematics (Unpublished Thesis), University of Massachusetts Lowell, America.

Gulikers, I., \& Blom, K. (2001). A historical angle, a survey of recent literature on the use and value of history in geometrical education. Educational Studies in Mathematics, 47, 223-258. https://doi.org/10.1023/A:1014539212782

Haverhals, N., \& Roscoe, M. (2010). The history of mathematics as a pedagogical tool: teaching the integral of the secant via Mercator's projection. The Montana Mathematics Enthusiast, 7(2-3), 339-360.

Hickman, F., \& Kapadia, R. (1983). A history of mathematics course for teachers. International Journal of Mathematical Education Science and Technology, 14(6), 753-761. https://doi.org/10.1080/0020739830140613

Ho, W. K. (2008). Using history of mathematics in the teaching and learning of mathematics in Singapore. Paper presented at the 1st RICE, Singapore: Raffles Junior College.

Horton, L. B. (2011). High school teachers' perception of the inclusion of history of mathematics in the classroom (Unpublished thesis), University of Massachusetts Lowell, America.

Huntley, M. A., \& Flores, A. (2010). A history of mathematics course to develop prospective secondary mathematics teachers' knowledge for teaching. Primus, 20(7), 603-616. https://doi.org/10.1080/10511970902800494

Jankvist, T. U. (2009). A categorization of the whys and hows of using history in mathematics education. Educational Studies in Mathematics Education, 71(3), 235-261. https://doi.org/10.1007/s10649-008-9174-9

Lawrence, S. (2006). Maths is good for you: web-based history of mathematics resources for young mathematicians and their teachers. Journal of the British Society for the History of Mathematics, 21, 90-96. https://doi.org/10.1080/17498430600803375

Leng, N. W. (2006). Effects of an ancient Chinese mathematics enrichment programme on secondary school students' achievement in mathematics. International Journal of Science and Mathematics Education, 4, 485-511. https://doi.org/10.1007/s10763-005-9017-4

Lim, S. Y. (2011). Effects of using history of mathematics on junior college students' attitudes and achievement, Retrieved from http://www.merga.net.au/documents/RP_SIEW.YEE.LIM_MERGA34-AAMT.pdf.

Lim, S. Y., \& Chapman, E. (2015). Effects of using history as a tool to teach mathematics on students' attitudes, anxiety, motivation and achievement in grade 11 classrooms. Educational Studies in Mathematics, 90(2), 189-212. https://doi.org/10.1007/s10649-015-9620-4

Liu, P. (2003). Do teachers' need to incorporate the history of mathematics in their teaching? Mathematics Teacher, 96(6), 416-421.

Marshall, G. L., \& Rich, B. S. (2000). The role of history in a mathematics class. Mathematics Teacher, 93(8), 704-706.

Nataraj, M. S., \& Thomas, M. O. J. (2009). Developing understanding of number system structure from the history of mathematics. Mathematics Education Research Journal, 21(2), 96-115. https://doi.org/10.1007/BF03217547

NCTM (2006). Historical topics for the mathematics classroom. Reston, VA: Author.

Panasuk, R. M., \& Horton, L. B. (2012). Integrating history of mathematics into curriculum: what are the chances and constraints? International Electronic Journal of Mathematics Education, 7(1), 3-20.

Siu, M. K. (2007). No, I don't use history of mathematics in my class. why? Retrieved from http://hkumath.hku.hk/ mks/10thICMI-MKS.pdf

Smestad, B. (2008). Teachers' conceptions of history of mathematics. Retrieved from 
http:/home.hio.no/ bjorsme/HPM2008paper.pdf

Swetz, J. W. (1997). Using problems from the history of mathematics in classroom instruction, In Swetz, F., Fauval, J., Bekken, O., Johansson, B., \& Katz, V. (Eds.), Learn from the masters. The Mathematical Association of America.

TTKB (2013). Secondary school mathematics curriculum in Turkey, Retrieved from http://ttkb.meb.gov.tr/www/ogretim-programlari/icerik/72

Tzanakis, C., \& Arcavi, A. (2002). Integrating history of mathematics in the classroom: an analytic survey, In Favuel, J., \& Van Manen, J. (Eds.), History in mathematics education (pp. 201-240), Netherlands: Kluwer Academic Publishers. https://doi.org/10.1007/0-306-47220-1_7

Wilson, P. S., \& Chauvot, J. B. (2000). Who? How? What? A strategy for using history to teach mathematics. Mathematics Teacher, 93(8), 642-45.

Wright, B. D., \& Stone, M. H. (1999). Measurement essentials (2nd ed.). Wilmington, DE: Wide Range.

Appendix 1. Correct and Incorrect Answers to the Test Items and Percentages

\begin{tabular}{llllll}
\hline Items & Cf & $\%$ & Wf & $\%$ & Correct Response \\
\hline $\begin{array}{l}\text { 1) Which two cultures are at the root of the decimal number system we } \\
\text { use today? }\end{array}$ & 3 & 31 & 97 & Indo-Arabic \\
\hline 2) Write the name of a woman mathematician. & 0 & 0 & 32 & 100 & $\begin{array}{l}\text { Maryam } \\
\text { Mirzakhani, } \\
\text { Hypatia, Sophie } \\
\text { Germain }\end{array}$ \\
\hline
\end{tabular}

3) He tried to calculate the circumference of the world. $\quad \begin{array}{llllll}24 & 75 & 8 & 25 & \text { Eratosthenes }\end{array}$

The prime number heart he developed is used in today's classrooms.

Who is this mathematician?

\begin{tabular}{lllllll}
\hline 4) What was the topic of the problem which led to the discovery of the & 6 & 19 & 26 & 81 & Rabbit
\end{tabular}
sequence $1,1,2,3,5,8,13, \ldots$ which is found in many places in the nature and is present in the book entitled Liber Abaci?

5) -In ancient Egypt, the value of ... was found by using the areas of a $\begin{array}{lllllll}24 & 75 & 8 & 25 & \text { Pi number }\end{array}$ square, regular octagon and circle.

-It takes its name from the first letter of the word circumference in Greek.

-It is also known as Archimedes constant.

-Throughout history, it was calculated differently by different civilizations.

Use the four statements above to find the term that goes in the blank.

$\begin{aligned} & \text { 6) Write the name of a mathematician who proved the Pythagorean } \\ & \text { theory, other than Pythagoras himself. }\end{aligned}$
$\begin{aligned} & \text { 7) Among past mathematicians, he is the one who is most associated } 11 \\ & \text { with geometry. }\end{aligned}$
He wrote the book Elements.
Postulate 5 in his book paved the way for spherical and elliptic
geometries.
Who is the mathematician whose qualities are listed above?

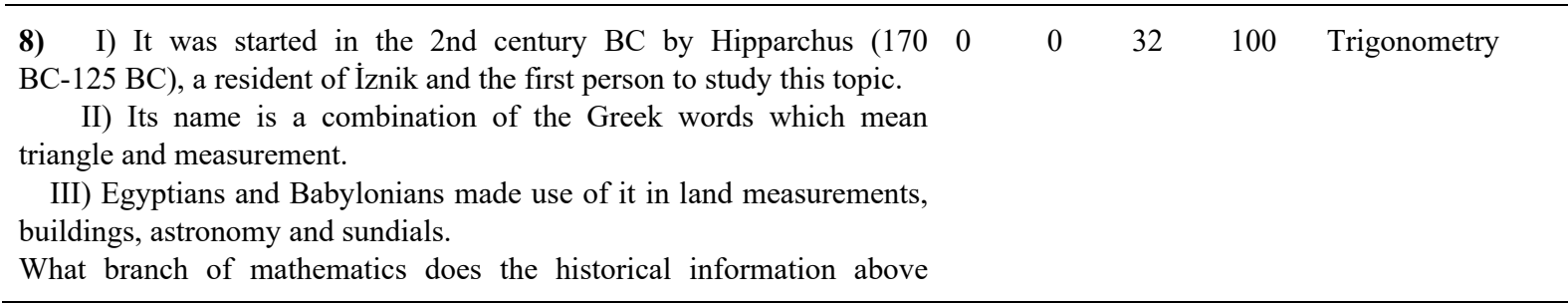


belong to?

9) - This country has one of the oldest known counting systems. $\quad \begin{array}{lllllll}11 & 34 & 21 & 66 & \text { Egypt }\end{array}$

- They developed a number system up to a million approximately

5000 years ago.

- Numbers and numerals consist of symbols.

- Below are 6 different symbols comprising their counting system:

\begin{tabular}{|c|c|c|c|c|c|}
\hline 1 & 10 & 100 & 1.000 & 10.000 & 100.000 \\
\hline I & $\cap$ & $\rho$ & i & 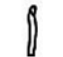 & \\
\hline
\end{tabular}

Which of the following civilizations do the qualities above describe?

10) - The word algorithm is derived from his name.
- He used the methods of balancing, simplifying and replacing in
solving equations.
Who is this mathematician?
$\begin{aligned} & \text { 11) - He was a French mathematician who lived in the 17th century. } \\ & \text { - He spent considerable time on a triangle consisting of numbers, }\end{aligned}$
which carved his name in humanity's mind.
$\quad$ - He set the foundations of the modern probability theory. He also
worked on conics and projective geometry.
$\quad$ - This triangle was found earlier by Omar Khayyam, and before
him, the Chinese had this knowledge too.
Who is this mathematician?

Cf: number of people who gave a correct response, Wf: number of people who gave an incorrect response

\section{Copyrights}

Copyright for this article is retained by the author(s), with first publication rights granted to the journal.

This is an open-access article distributed under the terms and conditions of the Creative Commons Attribution license which permits unrestricted use, distribution, and reproduction in any medium, provided the original work is properly cited. 